\title{
Mise en évidence de peptides antigéniques de la protéine Env du virus HIV
}

\author{
Armand Bensussan
}

Une des grandes particularités du lymphocyte $T$ est de reconnaître des peptides antigéniques non pas lorsqu'ils se présentent sous forme soluble comme le fait le lymphocyte $B$ mais lorsqu'ils sont présentés à la surface des cellules cibles par les protéines du complexe majeur d'histocompatibilité (CMH) [1-3].

En fonction de leur affinité particulière pour les molécules du $\mathrm{CMH}$ on distingue deux sous-populations de lymphocytes $\mathrm{T}$ : l'une de ces souspopulations cellulaires, normalement majoritaire, exprime l'antigène de différenciation CD4 et possède des récepteurs spécifiques capables de reconnaître l'antigène peptidique présenté par les molécules de la classe II du CMH. L'autre sous-population est composée de cellules $\mathrm{CD}^{+}{ }^{+}$dont le récepteur spécifique reconnaît l'antigène lorsque celui-ci est présenté par les molécules de la classe I du CMH. Les lymphocytes $\mathrm{CD}^{+}$ sont essentiellement des cellules effectrices de la cytotoxicité à médiation cellulaire alors que les cellules $\mathrm{CD} 4^{+}$, lorsqu'elles sont activées spécifiquement, sécrètent des lymphokines qui agissent sur d'autres types cellulaires et, de ce fait, sont principalement impliquées dans le contrôle et la différenciation des cellules du système immunitaire. A ce schéma général il existe des exceptions, notamment une minorité de lymphocytes CD4, qui peuvent acquérir, sous l'action de l'interféron $\gamma$, une activité cytotoxique [4]. Par ailleurs, des résultats récents semblent indiquer que les cellules suppressives qui expriment l'antigène de différenciation CD8 reconnaissent l'antigène associé aux molécules de la classe II du CMH [5].

Le virus de l'immunodéficience humaine ou HIV (human immuno-

drome de l'immunodéficience acquise, a un tropisme préférentiel pour les lymphocytes $\mathrm{CD}^{+}{ }^{+}$, la molécule $\mathrm{CD} 4$ étant elle-même le récepteur cellulaire spécifique du HIV, fixant le virus par l'intermédiaire de sa glycoprotéine d'enveloppe gp 120 La protéine virale d'enveloppe joue un rôle important dans la cellule cible du virus, notamment par un mécanisme analogue à celui de la fusion cellulaire par laquelle le virus se transmet de cellules à cellules : la molécule gp 120 à la surface d'une cellule infectée se lie aux molécules CD4 des cellules voisines. La fusion des membranes engendre une grosse masse appelée syncitium, limitée par une membrane et renfermant de nombreux noyaux. Les lymphocytes $\mathrm{CD}^{+}{ }^{+}$en sont les principales victimes; néanmoins le virus infecte d'autres populations de cellules comme les macrophages et les cellules gliales, qui peuvent exprimer très peu de molécules CD4. La formation de syncitia amplifie l'effet destructeur du virus et semble responsable de la disparition de ce "chef d'orchestre » du système immunitaire qu'est le lymphocyte $\mathrm{CD}^{+}$. En effet le lymphocyte $\mathrm{CD}^{+}$ activé spécifiquement est non seulement nécessaire pour amplifier une réponse humorale, mais est aussi essentiel pour induire la différenciation et la propagation des lymphocytes CD8 effecteurs de la cytoxicité[6], ces derniers étant indispensables à la défense de l'organisme contre les cellules infectées par le HIV.

Étant donné que l'utilisation d'un vaccin à base de virus tué semble actuellement devoir être écarté, il nous a semblé important d'identifier des peptides antigéniques de la protéine Env du HIV-l capables de stimuler les lymphocytes $\mathrm{CD}^{+}{ }^{+}$afin de les utiliser comme composants éventuels d'un vaccin contre le SIDA. D'autre part, sachant que les lymphocytes $\mathrm{CD}^{+}{ }^{+}$provenant d'individus HIV-l positifs asymptomatiques ont souvent une réponse proliférative à des antigènes spécifiques considérablement diminuée, nous avons préféré utiliser les lymphocytes $\mathrm{CD}^{+}$du sang périphérique d'individus sains volontaires pour être immunisés avec des virus recombinants de la vaccine contenant le gène de l'enveloppe du HIV-l.

Les lymphocytes du sang périphérique de 14 individus ainsi immunisés et réimmunisés in vivo six mois après avec des fragments contenant au moins $40 \%$ de l'extrémité $C$ terminale de la protéine gp 120 ont été stimulés in vitro par deux peptides synthétiques différents (correspondant à des segments particuliers de la protéine gp 120) dont il a été préalablement décrit qu'ils entraînaient une réponse proliférative dans un modèle murin [7]. Le peptide env-T1 correspond aux acides aminés 428443 (Lys-Gln-Ile-Ile-Asn-Met-TrpGln-Glu-Val-Gly-Lys-Ala-Met-TyrAla) alors que le second peptide env$\mathrm{T} 2$ correspond aux résidus 112-124 (His-Glu-Asp-Ile-Ile-Ser-Leu-TrpAsp-Gln-Ser-Leu-Lys) de la gp 120. Les résultats indiquent que, 40 jours après la deuxième immunisation, huit des 14 individus étudiés répondent au peptide env-Tl et quatre au peptide env-T2. La réponse au peptive env-T2 n'était pas attendue dans la mesure où le fragment de la protéine gp 120 utilisé lors du rappel ne contenaient pas la séquence 112-124 (env-T2) [8].

Dans le but de mettre en évidence une réponse proliférative spécifique des lymphocytes $\mathrm{CD}^{+}{ }^{+}$aux peptides de l'env-Tl, nous avons choisi deux individus, parmi les huit qui don- 
naient une réponse proliférative significative face aux peptides de l'env-Tl. La population $\mathrm{CD}^{+}$a été éliminée lors du prélèvement des lymphocytes du sang périphérique par lyse dépendante du complément en utilisant un anticorps spécifique anti-CD8. Le Tableau I indique que la population cellulaire du sang périphérique des individus 2 et 3 séparée des lymphocytes CD8 donne une réponse proliférative spécifique similaire à celle de la population non séparée. De plus, lorsqu'un anticorps anti-CD4 (OKT4) est rajouté au début de la culture cellulaire, une nette inhibition de la réponse à l'antigène env-Tl est observée. Ces résultats montrent clairement que le peptide correspondant aux résidus 428443 de la gp 120 est un motif antigénique pour les lymphocytes CD4 humains.

L'approche - qui consiste à définir des peptides viraux que les lymphocytes $\mathrm{CD}^{+}{ }^{+}$reconnaissent, dans le but de les inclure dans un vaccin qui aurait pour vocation de développer une réponse des lymphocytes $\mathrm{T}$ amplificateurs - est essentielle dans la défense de l'organisme contre toute agression d'un rétrovirus tel que le HIV

\section{Summary}

Antigenic peptides from Env-protein of human immunodeficiency virus

In the normal immune defense against virus, $\mathrm{CD}^{+}$helper T lymphocytes are necessary for the antibody response as well as the cytotoxic response performed by the $\mathrm{CD}^{+} \mathrm{T}$ lymphocytes. Therefore, it is important to define antigenic sites of the viral Env-protein of HIV to develop helper CD4 ${ }^{+}$cell immunity to this virus. We show that synthetic peptides of the viral envelope proteine gp 120 are able to induce in vitro $\mathrm{CD}^{+}{ }^{+} \mathrm{T}$ lymphocytes proliferation. For our study we use peripheral blood mononuclea cells from of human volonteers who had been immunized with a recombinant vaccinia virus containing the AIDS viral envelope gene and boosted with a recombinant fragment.

Tableau I

MISE EN ÉVIDENCE D'UNE PROLIFÉRATION CELLULAIRE DES LYMPHOCYTES CD4 EN RÉPONSE AU PEPTIDE ENV-T1 DE LA gp 120

\begin{tabular}{|c|c|c|c|c|}
\hline & \multicolumn{2}{|c|}{ Individu 2* } & \multicolumn{2}{|c|}{ Individu $3^{*}$} \\
\hline & $\begin{array}{c}\text { Cellules } \\
\text { non séparées }\end{array}$ & $\begin{array}{l}\text { Cellules séparées } \\
\text { des lymphocytes CD8 }\end{array}$ & $\begin{array}{c}\text { Cellules } \\
\text { non séparées }\end{array}$ & $\begin{array}{l}\text { Cellules séparées } \\
\text { des lymphocytes CD8 }\end{array}$ \\
\hline Milieu de culture ${ }^{* * *}$ & $145^{* *}$ & 233 & 621 & 507 \\
\hline $\begin{array}{l}\text { Milieu de culture } \\
+4 \mu \mathrm{M} \text { de peptide env-TI }\end{array}$ & 5312 & 4827 & 12356 & 13010 \\
\hline $\begin{array}{l}\text { Milieu de culture } \\
+4 \mu \mathrm{M} \text { de peptide env-T1 } \\
+100 \mathrm{ng} / \mathrm{ml} \text { OKT } 4\end{array}$ & 1460 & 1132 & 4916 & 4470 \\
\hline
\end{tabular}

* Les individus 2 et 3 ont été sélectionnés pour leur réponse proliférative importante au peptide env-T1. ** Incorporation de thymidine radioactive au jour 7 de la culture cellulaire. Chaque valeur (cpm) correspond à la valeur médiane de trois cultures identiques indépendantes. ${ }^{* * *}$ Le test de prolifération consiste d̀ cultiver $2.10^{5}$ cellules dans un volume final de $200 \mu \mathrm{l}$ de milieu de culture constitué de RPMI 1640, $10 \%$ de sérum de veau fotal et des antibiotiques.

\section{RÉFÉRENCES}

1. Zinkernagel R, Doherty P. H-2-compatibility requirement for $\mathrm{T}$-cell-mediated lysis of target cells infected with lymphocytic choriomeningitis virus: different cytotoxic T-cell specificities are associated with structures from H-2K or H-2D. J Exp Med 1975; 141 : 1427-36.

2. Babbitt B, Allen P, Matsueda G, Haber E, Unanue $E$. Binding of immunogenic peptides to Ia histocompatibility molecules. Nature 1985 ; $317: 359-61$.

3. Buus S, Sette A, Colon SM, et al. Isolation and characterization of antigen-Ia complexes involved in $\mathrm{T}$-cell recognition. Cell $1986 ; .47$ : 1071-7.

4. Bensussan A. CD4 cytotoxic T lymphocytes differentiation. Biochimie 1988; 70 : 937-40.

5. Shinohara $\mathbf{N}$, Watanabe $\mathbf{M}$, Sachs $\mathbf{D H}$, Hozumi N. Killin of antigen-reactive B cells by class II-restricted, soluble antigen-specific CD8 ${ }^{+}$cytotoxic T lymphocytes. Nature 1988 ; 336 : 481-4.
6. Chouaib S, Bensussan A, Termijtelen AM et al. Allogeneic T-cell activation triggering by MHC class I antigens. J Immunol 1988 ; $141: 423-9$

7. Cease KB, Margalit H, Cornette JL, et al. Helper $\mathrm{T}$-cell antigenic site identification in the acquired immunodeficiency syndrome virus gp 120 envelope protein and induction of immunity in mice ot the native protein using a 16-residue synthetic peptide. Proc Nat Acad Sci USA 1987; 84 : 4249-53.

8. Berzofsky JA, Bensussan A, Cease KB, et al. Antigenic peptides recognized by $\mathrm{T}$ lymphocytes from AIDS viral envelope-immune humans. Nature 1988 ; 334 : 706-8.

\section{Remerciements}

Je voudrais remercier ici D. Zagury (Institut Pierre-et-Marie-Curie, Paris, France), et J.A. Berzofsky (NCI, Bethesda, USA) sans lesquels ce travail n'aurait pu être réalisé.

\section{ADRESSE}

A. Bensussan : chargé de recherche. INSERM U. 93, Hôpital Saint-Louis, Centre Hayem, 1, avenue Claude-Vellefaux, 75010 Paris Cedex, France.
TIRÉS A PART

A. Bensussan. 